Article

\title{
Media Work as Field Advancement: The Case of Science Media Center Germany
}

\author{
Christopher Buschow *, Maike Suhr, and Hauke Serger \\ Faculty of Media, Bauhaus-Universität Weimar, Germany \\ * Corresponding author (christopher.buschow@uni-weimar.de)
}

Submitted: 30 April 2021 | Accepted: 2 August 2021 | Published: 20 January 2022

\begin{abstract}
In the wake of the news industry's digitization, novel organizations that differ considerably from traditional media firms in terms of their functional roles and organizational practices of media work are emerging. One new type is the field repair organization, which is characterized by supporting high-quality media work to compensate for the deficits (such as those which come from cost savings and layoffs) which have become apparent in legacy media today. From a practice-theoretical research perspective and based on semi-structured interviews, virtual field observations, and document analysis, we have conducted a single case study on Science Media Center Germany (SMC), a unique non-profit news start-up launched in 2016 in Cologne, Germany. Our findings show that, in addition to field repair activities, SMC aims to facilitate progress and innovation in the field, which we refer to as field advancement. This helps to uncover emerging needs and anticipates problems before they intensify or even occur, proactively providing products and tools for future journalism. This article contributes to our understanding of novel media organizations with distinct functions in the news industry, allowing for advancements in theory on media work and the organization of journalism in times of digital upheaval.
\end{abstract}

\section{Keywords}

digital journalism; field repair organization; journalism; media work; news media start-up; Science Media Center Germany

\section{Issue}

This article is part of the issue "New Forms of Media Work and Its Organizational and Institutional Conditions" edited by Salla-Maaria Laaksonen (University of Helsinki) and Mikko Villi (University of Jyväskylä).

(C) 2022 by the author(s); licensee Cogitatio (Lisbon, Portugal). This article is licensed under a Creative Commons Attribution 4.0 International License (CC BY).

\section{Introduction}

Along with its technological, economic, and societal shifts, journalism's production structures and practices are also undergoing profound transformation (Alexander, 2015; Buschow, 2020a; Reese, 2020). Financial upheavals in the industry have led to cost cutting, downsizing and layoffs, the discontinuation of entire publications, and a significant increase in atypical, precarious forms of media work (Deuze \& Witschge, 2020; O’Donnell \& Zion, 2019).

One response to this transformed environment comes in the form of digital-native news media startups which attempt to mitigate the deficits and challenges of the contemporary news market (e.g., Buschow, 2020b; Deuze \& Witschge, 2020; Konieczna, 2018). While most of these start-ups are created to deliver identical or similar journalism to that produced by traditional media firms (Buschow \& Suhr, 2022), today's field of journalism also includes entirely new types of organizations, characterized by conducting alternative activities and structurally different forms of media work, thus fulfilling a novel functional role in the industry. Since an industry's organizational diversity is a central prerequisite for successfully dealing with changing environmental conditions (Hannan \& Freeman, 1989), journalism studies need a broad overview of the changing organizational field and a deep understanding of recently-emerging media organizations. However, current journalism research lags behind in exploring such non-traditional organizations, as most existing 
literature continues to focus on the digital transformation within legacy companies and newsrooms (Deuze \& Witschge, 2020).

In this article, we address the prevailing research gap in journalism studies by shedding light on a novel type of media organization, established to support and stimulate professional journalism and thus ensure highquality journalistic work in a digitalized media environment. We immerse into the unusual case of Science Media Center Germany (SMC), a non-profit, primarily foundation-funded start-up based in Cologne, Germany, and launched in 2016. With around 20 full-time employees and more temporary staff, SMC does not produce its own media content but provides specific "raw material" (SMC, 2021) such as expert statements, assessments and background information on science-related issues and publications, as well as tools and further measures supporting the work of (science) journalism. In doing so, SMC compensates for the deficits that are evident in many legacy media companies today ("field repair"; Konieczna, 2018) while aiming to facilitate progress and innovation in the field (which we term "field advancement"). Furthermore, to deliver its products and services, SMC has developed an innovative organizational design - a constellation of journalistic insiders and outsiders - that differs from traditional ways of working in the news industry. Despite its novelty in Germany (and possibly also worldwide), SMC has been successful so far and grown substantially since its incorporation, especially given the recent Covid-19 pandemic, in which it has become an essential resource for many of its 1,200 accredited journalists (Broer, 2020). This article asks the following research question:

RQ: What characterizes SMC as a new type of organization in (science) journalism?

Based on a practice-theoretical research approach, we have conducted an empirical case study on the role of SMC in today's digitalized journalism landscape, as well as on its internal structures and practices, examining the kind of media work that is achieved in this organization. Our study is based on a triangulation of virtual ethnographic fieldwork, semi-structured interviews, and document analysis. With an in-depth analysis of the single case of SMC, the article contributes to our understanding of novel media organizations with distinct functions in the news industry, allowing theory building for journalism and media work in times of digitalization.

\section{Theoretical Background}

Digitalization fuels the emergence of novel organizations in the news industry. These organizations are a response to current upheavals since they pave the way for journalism's organizational adjustments to a changing market environment (Buschow, 2020b; Deuze \& Witschge, 2020). Consider, for example, news start-ups, many of which have been established to counteract economic cost-cutting and downsizing tendencies in legacy companies (Konieczna, 2018). On the other hand, new organizations, as collective social agents, are themselves drivers of change that lead to transformation and renewal in journalism through their myriad activities.

New organizations are situated in the changing journalistic field, i.e., the set of organizational actors that constitute the production of news (DiMaggio \& Powell, 1983; Holton \& Belair-Gagnon, 2018). Current research typically applies Bourdieu's field theory (Bourdieu, 1998), focusing primarily on the entry of digital-peripheral actors ("strangers") to the journalistic field, on the boundary work of legacy media companies, and on the resulting power struggles over legitimation (e.g., Eldridge, 2018; Tandoc \& Jenkins, 2017). By following an organizational-sociological perspective on the journalistic field (e.g., Hannan \& Freeman, 1989; Scott, 2013), as we do here, journalism studies can instead identify novel types of organizations that differ considerably from traditional media firms in terms of their functional roles in the industry and organizational practices of media work.

Because they are rare and exceptional cases by definition, a research gap concerning these novel types of media organizations persists. However, for the progress of knowledge and theory building in journalism studies, in-depth investigations are of great importance for better understanding their contributions to the field and how they drive change, as well as how media work is accomplished in these organizational settings. Against this background, our article focuses on the relatively new, non-profit media organization SMC.

\subsection{SMC's Functional Role in the Journalism Field}

SMC arguably constitutes a novel type of media organization: neither a legacy media player (such as a publisher or broadcaster) nor a traditional news agency or wire service, but performing a functional role somewhere in between and beyond. As part of a larger global movement of science media centers in, amongst other countries, Great Britain, Australia, and New Zealand, it has essentially pioneered a model of supporting infrastructure and services, often referred to as an intermediary organization between the fields of science and journalism (Broer, 2020; Rödder, 2015). From previous studies we have a solid understanding of how SMC moderates the relationship between the fields of science and journalism, acting as a "knowledge broker" (Broer, 2020) and an "organized contact system" that institutionalizes relationships, potentially leveraging trust between the two sectors (Rödder, 2020). However, there is a lack of insight into what SMC does specifically for journalism and how it might differ from other organizations in the field.

This is particularly surprising given that, unlike the British SMC, which was founded to act as a "press office for science" (Hettwer et al., 2012), the German $\mathrm{SMC}$ is rooted in journalism, with the German Science 
Journalists' Association (Wissenschafts-Pressekonferenz e.V., WPK) as one of its founding partners (Hettwer et al., 2013). Instead of solely promoting scientific studies through public relations, its focus on evidence-based information regularly brings about critical engagement with science, e.g., through "agenda-blocking," a practice that is employed when a publication's scientific quality is questionable and should not receive widespread attention (Broer \& Pröschel, 2021). Originating from the field of journalism and still organized under journalistic leadership, SMC's primary goal is to provide supporting services and nurturing conditions for (science) journalism, which is struggling to keep up with the ever-increasing flood of scientific knowledge which collides with journalism's economic constraints (Broer \& Pröschel, 2021; Hettwer et al., 2013).

In journalism studies, such a supporting function in the industry has been described as field repair (i.e., attempts to fix journalism from within), primarily by stimulating traditional legacy structures and quality content production, "directly, by providing the kinds of public affairs coverage seen to be lacking, and indirectly, through institution-building meant to promote such coverage in the news industry as a whole" (Graves \& Konieczna, 2015, p. 1968; Konieczna, 2018). Classic examples of novel field repair organizations are non-profit, foundation-funded news ventures such as ProPublica, which are explicitly created to substitute activities that were previously performed by legacy media but have been cut to save costs. Field repair organizations are remarkable in that they repackage certain journalistic activities that were traditionally combined in a typical media organization into new organizational units.

Today, SMC seeks to improve rather than challenge journalism. However, as a non-traditional journalism actor, it cannot simply be classified as operating either inside or outside of the journalistic field based on the current state of research (Eldridge, 2018; Holton \& Belair-Gagnon, 2018). For instance, while the work of SMC's newsroom is committed to journalism's values (Broer, 2020; Broer \& Pröschel, 2021), some of its media workers have backgrounds in fields other than journalism. The latter could be described as "interlopers" (Eldridge, 2018) or "strangers" (Holton \& Belair-Gagnon, 2018), those "who have not belonged to traditional journalism practice but have imported their qualities and work into it" (Holton \& Belair-Gagnon, 2018, p. 70). The in-depth examination of new journalistic organizations such as SMC might help to better understand their novel position in and contributions to the news industry, and how this is related to a more general change in the field. Thus, we propose the first sub-research question of our article:

SRQ1: What is the functional role of SMC in (science) journalism?

\subsection{SMC's Practices of Media Work}

To perform a new role in the industry and make novel contributions to journalism, organizations must adopt new and alternative forms of media work, i.e., "activities undertaken by media professionals in order to advance the success of media products and services" (Malmelin \& Villi, 2017, p. 1).

Practices that characterize field repair organizations in general include sharing news content, resources, knowledge, and methods with legacy industry actors under the banner of journalistic reform (Graves \& Konieczna, 2015, p. 1970). Specifically, the practice of news sharing stands out when a field repair organization passes ready-made investigations and journalistic content pieces to established media for publication, free of charge (Hermida \& Young, 2019). Another typical practice is fact-checking (i.e., attempts to increase general journalistic quality within the field). However, because of the relatively close collaboration with existing industry structures inherent in such practices, field repair organizations are generally seen to be limited in improving and innovating journalism (Konieczna, 2018).

To investigate the kind of media work through which SMC accomplishes its role in German (science) journalism, we have applied a practice-theoretical research perspective (e.g., Buschow, 2020a; Ryfe, 2018; Witschge \& Harbers, 2018). Such a viewpoint understands organizations as fundamentally constituted by social practices (i.e., concrete, situated patterns of action) which are regularly and repeatedly enacted by organizational members, thereby shaping the organization (Nicolini, 2012; Schatzki, 2005). Analyzing social practices allows for the open and exploratory discovery of new forms of media work that might not have been recognized when viewed through the lens of more traditional journalism theories (Witschge \& Harbers, 2018). As we know little about the practices that constitute the German SMC, we propose as our second SRQ:

SRQ2: Which essential practices of media work enable SMC to fulfill this role?

\section{Method}

\subsection{Selection of the Case}

We deliberately selected the German SMC, assuming it to be, in its entirety, a unique type of media organization (Broer, 2020; Rödder, 2020). The objective of our exploratory study was not only to provide a rich description of SMC, but also to make sense of its functional role in the changing field of journalism (SRQ1) and through which kind of media work this role can be achieved (SRQ2). We followed a qualitative single case study research design to gain the deepest possible insight into this novel, largely unexplored organization (Eisenhardt, 1989; Yin, 2018). Single case studies are 
particularly suitable for an in-depth understanding of the complex and dynamic nature of a research phenomenon, thus enriching theory development (Ridder, 2020). While a multiple case study design has the advantage of replication being able to increase the robustness of the theory developed, its requirement that a variety of instances be examined and compared makes such a research strategy impractical in a unique organizational setting like the German SMC.

\subsection{Data Collection}

Our article aims to provide a deep understanding of SMC through the triangulation of multiple research perspectives, collecting and analyzing a wide variety of data over a period of about three months (November 2020 to January 2021). To gain the most comprehensive insights, and guided by methods of news production studies (Cottle, 2007; Jordaan, 2020), we combined (virtual) field observations with document analysis and a series of semi-structured interviews. Table 1 gives an overview of our data sources.

Starting the research process with document analysis (Bowen, 2009), we drew on several public and internal documents which allowed us to develop an initial understanding of SMC's specific self-perception and the way it organizes its work. Throughout the research process, these documents were repeatedly revisited for contextual information. We also gained access to SMC's internal Slack, its online collaborative software (Bunce et al., 2018), which proved particularly useful for observing ongoing interactions and accessing past communication to chronologically track organizational developments.
Due to the Covid-19 pandemic and resulting contact restrictions in Germany, at the time of data collection, large parts of SMC's work took place in digital spaces. In response, we conducted virtual ethnographic fieldwork through qualitative observations (Cottle, 2007; Jordaan, 2020; Usher, 2016). Instead of being on-site, all three researchers participated in a variety of different video conferences over three weeks. We focused primarily on observing routines at daily editorial conferences and weekly team meetings, but also joined strategy meetings with top management and department heads. Furthermore, we shadowed an editor for approximately two hours during the preparation of the daily editorial conference (Usher, 2016). In such a virtual ethnography, spontaneous meetings and hallway conversations cannot be observed, nor is there the opportunity for ad hoc questions. Observing the virtual environment proved helpful nonetheless because the fieldwork period could be extended flexibly, and observer influence was less prevalent (Nørskov \& Rask, 2011). During the process, each researcher took field notes individually and then generated observation protocols, which we reviewed and discussed daily within the team to avoid interpretative biases. The key findings from the virtual ethnography became a foundation for preparing our semi-structured interview guides.

In addition to our observation, we conducted 15 semi-structured interviews. This resulted in a total of approximately 20 hours of audio material. Seven interviews were conducted with key informants in management roles, and we applied a semi-structured interview guide including questions about SMC's self-perception, strategy and product portfolio, and future plans. These

Table 1. Data sources.

\begin{tabular}{lll}
\hline Method & Data & Processing \\
\hline $\begin{array}{l}\text { External and internal } \\
\text { documents }\end{array}$ & Public data (e.g., website, content products, newsletter, Twitter) & Close reading, \\
& $\begin{array}{l}\text { Six internal documents (e.g., organization chart, editorial handbook, } \\
\text { presentation decks) }\end{array}$ & $\begin{array}{l}\text { integration in case } \\
\text { study database }\end{array}$
\end{tabular}

Three evaluation-related documents from SMC (e.g., screenshots, survey results)

Minutes of team meetings

(Virtual) ethnographic Field notes from over 20 meetings observed over several weeks fieldwork

15 observational protocols

Excerpts from Slack channels

Semi-structured interviews

\section{Seven interviews with management staff}

Three interviews with members of the editorial department

Three interviews with members of the lab department

Two interviews with shareholders
Anonymization, consolidation of key learnings, integration in case study database

Transcription of audio recordings into text, anonymization, integration in case study database 
findings were complemented by six interviews with subordinate employees, which were conducted after the observation to reflect on and deepen initial findings, thus compensating for the limitations of the virtual fieldwork. These interviews focused on the operational level and workflows within the department, as well as the goals of the departments and SMC in general. Finally, two interviews were conducted with shareholders. References to quotes from these interviews in the following are marked with (I\#), where \# stands for the respective interview number.

\subsection{Data Analysis}

During data generation, we continuously added all the material obtained (see Table 1) to a case study database that we built using ATLAS.ti, a computerassisted qualitative data analysis tool. Over the process of data collection, in several (in-person and virtual) workshops we regularly discussed interesting aspects, emerging narratives, and findings within our research team, with the aim of building consensus and unifying the researchers' knowledge.

All three data types (documents, field notes, and interview transcripts) were included in qualitative analysis, following recommendations on good practice in analyzing, indexing, and coding qualitative data (Eisenhardt et al., 2016; Miles et al., 2014; Saldaña, 2016). The first cycle coding, i.e., the initial assignment of (mostly descriptive) codes and sub-codes to similar data points to arrive at clusters of analyzable material (Saldaña, 2016), was carried out by the article's second author, partially reviewed by and discussed with the article's first author. For guidance, our research questions provided an initial coding tree (a "start list" of codes; cf. Miles et al., 2014), that was inductively expanded, differentiated, and revised throughout the iterative data analysis process. During the second cycle coding, i.e., the grouping of initial codes to develop categories and concepts of higher levels (Miles et al., 2014), data analysis workshops within the research team were conducted, e.g., for reviewing categories, discussing rival hypotheses, and arriving at common interpretations (Ridder, 2020; Yin, 2018).

Regarding SMC's role in (science) journalism (SRQ1), the first coding cycle identified its contributions to journalism. Initial codes comprised typical journalistic tasks, such as "assessing" and "processing" information/data and "identifying expertise," but also more specific contributions, like "meta-knowledge" or "networking." In the second coding cycle, these codes were refined, subsumed, and grouped by the research team, eventually resulting in the final data structure (see Table 2).

In terms of practices of media work (SRQ2), our objective was not to identify general differences to established media organizations but rather to discover-among the various patterns of action that shape everyday work at SMC - the organizational practices that, in essence, help SMC fulfill its functional role in the field of journalism.
Initial codes comprised "work organization," "issue selection," "product/tool development," "cooperation," and "contact." In a further workshop, the research team identified the main practices essential to SMC's accomplishment of its functional role (see Section 4.2). For both research questions, theory building from the case was cross-checked in ongoing discussions within the research team to establish the most reasonable interpretation of our data (Ridder, 2020).

\section{Results and Discussion}

\subsection{Functional Role of SMC}

Our research perspective on SMC enhances its prevailing characterization as an intermediary organization in science communication (Broer, 2020; Rödder, 2020). Its contributions to journalism go beyond the role of a knowledge broker or an organized contact system in-between actors from the fields of science and journalism, and also clearly exceed the typical activities of legacy media organizations. Correspondingly, SMC is described in our interviews as a "service provider for the common good" (104) and as "journalism's good spirit" (I13). Table 2 sums up the wide spectrum of SMC's contributions to (science) journalism that characterize its functional role in the news industry.

As Table 2 highlights, its functional role ranges from an individual level (support for accredited journalists) to the field level (public support for science journalism, coordinating collaborative investigations). In particular, SMC's direct supporting services for news work resonate with the concept of field repair (Graves \& Konieczna, 2015; Konieczna, 2018), so SMC can be understood as a field repair organization by meeting the signifying practice of news sharing. This is evident from exemplary content products such as Rapid Reaction and Fact Sheets, which are forms of news sharing, even though they are not end products that publishers can distribute as is, but "raw materials" (I13). These take the form of only slightly edited expert statements and background knowledge, and aim to help science journalists finding a starting point for further investigation and news production.

However, as we can see from the portfolio of SMC's activities (Table 2 ), this novel organization not only aims at field repair but also what we term "field advancement." Whereas field repair describes more traditional journalistic services performed by new actors (e.g., news non-profits) for traditional structures (as is the case with content products such as Rapid Reaction and Fact Sheets), with field advancement we refer to new actors performing new services for journalism, thereby facilitating progress and innovation in the field, advancing what journalism can be, how journalists can work, and what journalism can accomplish (Zelizer, 2017).

SMC discovers emerging needs and anticipates problems before they intensify or even occur, proactively providing products and tools for future journalism. This 
Table 2. Contributions of SMC to (science) journalism.

\begin{tabular}{ll}
\hline Contributions & Exemplary products, tools, and initiatives \\
\hline $\begin{array}{l}\text { Supporting services for news work } \\
\begin{array}{l}\text { Identification and communication of } \\
\text { scientific expertise }\end{array}\end{array}$ & $\begin{array}{l}\text { Expert Explorer: a software tool to help journalists identify experts in the } \\
\text { biomedical area }\end{array}$ \\
$\begin{array}{ll}\text { Evaluation of scientific topics and new } \\
\text { publications }\end{array}$ & $\begin{array}{l}\text { Rapid Reaction: a content product that circulates expert statements on the } \\
\text { latest science-related issues and events among accredited journalists }\end{array}$ \\
$\begin{array}{ll}\text { Background } \\
\text { knowledge/contextualization }\end{array}$ & $\begin{array}{l}\text { Fact Sheets: a content product that provides an overview and background } \\
\text { information on complex science issues }\end{array}$
\end{tabular}

Identification and anticipation of public (science) issues

Provision of complex data and large data sets

Overview of new publications

Time advantage

Qualification, education, and training of journalists and media outlets

Consulting of media organizations and individual journalists

Sharing statistical expertise and enhancing data literacy with journalists, such as in Corona-related discussions

Meta-knowledge for determining expertise

Organization of coordinated investigations and reporting

Promotion of congruent

reporting/topic development

Operation Explorer: a collaborative (data) investigation developed and led by SMC in partnership with local media outlets and journalists to simultaneously publish on a certain topic (in this case, operations in German hospitals)

Public support of science journalism

Raising awareness for evidence-based science communication

Networking the science journalism community

becomes evident in its contributions to organizing coordinated investigations (such as Operation Explorer), to journalists' education, and to the development of new tools for information extraction and the adoption of machine learning procedures for journalism. Some examples of such tools are PRIOR, a piece of software for identifying potentially relevant scientific studies (only used in-house so far), and the Corona Publication List, currently being converted into a database to operate as a "structured journalism" or "atomized news" product (Caswell, 2019; Jones \& Jones, 2019). Interviews with management also indicate that SMC plans to strengthen field advancement in the future $(102 ; 114 ; 115)$, e.g., by experimenting with new forms of structured journalism, a potential "paradigm shift" (I02) in journalism which SMC hopes to play a central role in.
Unlike other field repair organizations, which are generally seen as limited in improving and innovating journalism due to their close collaboration with traditional actors (Konieczna, 2018), SMC can bridge this barrier by combining field repair with field advancement under one organizational structure. When we look at its field advancement arm, SMC tends to resemble parts of an (academic) media lab, i.e., an organizational structure specifically built for journalism innovation (Mills \& Wagemans, 2021).

\subsection{Organizational Practices of Field Advancement}

Our research stresses that supporting journalism through field advancement becomes possible for SMC through a unique set of organizational practices, which we refer 
to as internal exchange (4.2.1), field monitoring (4.2.2), external collaboration (4.2.3), and tool/product development (4.2.4). While these practices are not inherently new, they are unique in terms of their combination and in being accomplished specifically to advance the field.

\subsubsection{Internal Exchange}

SMC is characterized by specific practices of internal exchange. These constitute its organizational design and the new forms of media work it pioneers. The organization is divided into three departments: (a) the newsroom, an editorial department of about eight media professionals that is responsible for researching, processing, and providing content such as expert statements and background information in the form of "raw material"; (b) the lab, with a staff of nine, primarily engaged in software development; and the recently launched (c) innovation department, which is still in the process of being set up.

Due to this unique organizational structure, media workers with both traditional and non-traditional backgrounds (e.g., science, software development, project management, statistics) gather at SMC. Some of the staff (especially those from the lab) could be characterized as strangers (Holton \& Belair-Gagnon, 2018), interlopers (Eldridge, 2018), or hacker journalists (Usher, 2016), whereas most newsroom employees have a background in journalism. Its workforce of insiders and outsiders is yet another indication that SMC operates both from within and beyond the field of journalism.

While the newsroom allows the organization to collaborate closely with the traditional journalistic field, the lab is not simply a support unit that delivers services for the journalistic nucleus. On the contrary, it independently develops new tools and technologies for journalism (see Section 4.2.4), both in cooperation with the newsroom and external (mostly academic) project partners. Staff from the lab approach journalistic problems in different ways, including an experimental, developmentcentered approach or by "tinkering" (cf. Lewis \& Usher, 2013). An editor explains:

I think that the way we deal with [SMC's] mission differs between newsroom and lab. Because the newsroom looks at the content, of course, and the lab looks at how it can support this, through software that is developed or through research projects. (I07)

To make use of these divergent approaches and working cultures, there is a set of practices for internal exchange and cooperation. Practices of internal cooperation between these units range from simple technical support to joint product development processes, with the latter occurring in both ad hoc and planned ways. An example of collaborative product development is the Corona Daily Report, an editorial product created together with a statistician who is an employee of the lab (102; 107). Day-to-day collaboration relies on an informal exchange, resulting in the lab providing ad hoc technical support that enables the newsroom to solve its problems in a leaner, faster, and more flexible way (I10).

While the newsroom operates under greater structural and time constraints due to its daily editorial routines (for a detailed account, see Broer, 2020), the lab enjoys a high degree of freedom. As the deputy editor in chief puts it: "We somehow have more of an outside mission. That is, to get the material out there, to supply the journalists. There is more pressure to deliver something for us than for the lab" (106). The lab's relative freedom allows for basic research practices which, at best, prove useful later in the development of new (software) products. The head of the SMC lab describes a situation in which he dealt with language models for machine learning, at first only as a "side project" which he "found interesting" (102), but which he was later able to use as input for a collaborative project.

As we can see from the SMC lab, media professionals' work in novel organizations does not necessarily have to involve content creation, but can still be essential to journalism's success. Because they are only loosely coupled with legacy media, both the lab and the innovation department have the potential to overcome barriers to innovative capacity faced by field repair organizations that interact closely with the traditional field (Konieczna, 2018).

\subsubsection{Field Monitoring}

SMC closely monitors science (e.g., publications and pre-prints of scientific journals) and news coverage to identify public issues, partly with the help of specially designed software tools and unique work procedures (Broer, 2020). While the monitoring of sources and events certainly qualifies as classic journalistic practice (e.g., Gans, 1980; Tuchman, 1973), SMC also carefully monitors the struggles and needs of the journalistic field as a prerequisite for its functional role. One interviewee, a shareholder, explains the unique and essential practice of field monitoring (which enables SMC to define and continuously refine its goals and position) as follows:

Ideally, SMC would make journalism better. In the current world, it mainly serves to make sure it doesn't get worse. Preventing it from getting worse or helping it to get better depends on how journalism evolves, independently of SMC. This means that SMC has to be sensitive enough to see what is happening in the journalistic system. (I13)

Sensitivity and flexibility are also required for the current offerings and products. A lab member stresses the need to constantly ask: "Is what we offer still what is needed in the field?" (109). Currently, field monitoring as a new form of media work is not institutionalized in such a way that it is assigned to a specific unit, although the newly established innovation department is expected to take over this practice. 
While field monitoring is immanent in aligning new products to journalism's needs, it also means constantly questioning whether field repair and advancement are still enough, or if legacy media need to be substituted. SMC considers a scenario in which the prevailing journalism fails irreparably, and where SMC itself could become a provider of media products for end users. However, this would again only be a reaction to the field's developments, as a staff member stresses: "At the moment, it is absolutely not our task. But it would logically be our task, if one day it becomes necessary, I would say" (105). Certainly, this would then create a new competitive relationship with legacy media, challenging the existing structures of the field and leading to potential power struggles (Bourdieu, 1998).

\subsubsection{External Collaboration}

The practice of field monitoring is only feasible because SMC is involved in a wide variety of networks and communities. These range from more traditional science journalism actors, such as the German Science Journalists' Association (WPK), actors of science communication (universities, institutes) to think tanks (e.g., Siggener Kreis, a science communication network) and industry conferences (e.g., SciCar; see Table 2). Through the practice of networking, SMC can closely monitor journalism's situation and positions itself as a "player in the field of science journalism" (106), publicly advocating for science journalism. Moreover, through collaborative projects, SMC gains insights and provides input into the broader organizational environment. Referring to a current research project in cooperation with some actors from science communication, an editor explains:

We are involved, among others, to provide insights and to establish contacts to important data providers and simply to have some contacts to all the journals and science journalists and science communicators... to have a view of the big picture. (I07)

Since all the outputs of the organization are intended as a service to the field, both inputs and work procedures must also be closely linked to it. To do so, SMC generally bases its media work on practices of collaboration with external actors and a culture of participation. For example, openness and participation are evident in the collaborative investigations organized by SMC. Here, journalists are invited to work collectively on large and complex datasets, such as those based on the software tool Operation Explorer (see Table 2), to break material down to local news stories. In workshops, SMC staff guide journalists through the tool and instruct them in how to work with data, thereby educating journalists. The lab also collaborates with external project partners, mainly from academia (journalism and media studies, computer science) in long-term research projects that are broad in scope and aim to develop software tools and working methods for future (science) journalism (109). These collaborations are considered especially important for technology transfer, as the managing director explains (I15). The resulting software will be released under open-source licenses to encourage wider use in the field (102).

Through its practices of external collaboration, SMC also contributes to thinking media work anew and, following the approaches of many other news non-profits, advancing a general mindset of collaboration and sharing resources within the highly competitive field of journalism (Graves \& Konieczna, 2015). The head of lab refers to "knowledge commons" that he aims to establish more widely as a way of thinking in journalism: "[I am working] that this kind of thinking is promoted, because I think that it makes science journalism in general somehow sustainable, keeps it powerful, keeps it effective" (I02).

\subsubsection{Tool and Product Development}

In the development of tools and products for the journalistic field, practices of field monitoring, external collaboration, and internal exchange are constitutive. New tools and products can be based on the observation of current shortcomings in the field: "The basic idea arises from a problem," as the head of the editorial department states (106). Often, these problems can be observed in SMC's newsroom itself. Examples of internal challenges being addressed with software developed in-house include PRIOR, a tool to automatically scan and categorize incoming announcements for new publications, and Expert Explorer (see Table 2), a database for finding experts in the biomedical area.

These examples demonstrate the ongoing technologization of SMC's (science) journalistic work practices, which are standardized and automated (where possible) to compensate for challenges such as information overload. Expert Explorer shows how tools initially created for internal editorial use only are eventually made available to the entire field after thorough testing. This is rarely the case today, but in the interview with the lab's department head (102), it was confirmed that this is a key future strategy for opening up new ways of working in journalism.

New tools and products developed by SMC can also be based on the anticipation of emerging needs in journalism, as described in Section 4.2.2, under practices of field monitoring, as well as on observations of the latest technological trends, as the lab's department head highlights: "The most important thing, I think, is to put yourself on the front lines of technological development and see what can be transferred to science journalism" (I02). As indicated in Section 4.2.3, external collaborations are key in testing and transferring new technological trends to journalism. In these joined projects, the acquisition of research funds together with science institutions is often an essential practice for carrying out research in which new software can then be developed. 


\section{Conclusions and Outlook}

Through a multi-method qualitative investigation into the single case study of SMC, this article has presented an in-depth account of a novel, unusual type of media organization, focusing on its functional role as a supporting infrastructure in the news industry (SRQ1) and on the essential organizational practices that characterize its forms of media work (SRQ2). The aim of our study was not only to broaden the spectrum of media organizations in today's digital environment by including an additional type, but also to empirically contribute to theory development in journalism studies and research on media work.

Our article has introduced the theoretical concept of field advancement to explore SMC's unique contributions to (science) journalism. In the case of SMC, we identified four essential practices that facilitate field advancement: internal collaboration, field monitoring, external cooperation, and tool/product development. These ensure that SMC works closely with the field while operating relatively independently of industry constraints. The concept of field advancement helps to capture and understand the activities of new organizations that seek to not only repair traditional journalism by compensating for emerging deficits and stimulating quality media production ("field repair"), but also to innovate in and renew journalism, thus securing pathways to a better future for the profession. Therefore, SMC does not solely resemble field repair organizations such as ProPublica, but also incorporates certain organizational features of specific media labs, structures built to create, catalyze, and diffuse journalism innovation (Mills \& Wagemans, 2021).

SMC furthermore exemplifies how the upheaval in the news industry affects media work. Novel types of media organizations are deliberately created to substitute some of the activities of legacy media outlets that they no longer conduct (due to cost-cutting measures, for example) and to explore entirely new tasks which were not feasible in pre-digital times. As a consequence, organizational innovations such as SMC also reconfigure their media professionals' ways of working and the content of their work. In the case of SMC, media work does not primarily involve the creation of content products for end users, but rather a variety of practices that go beyond the process of media production. Against this background, our study enhances the prevailing understanding of media work in the literature (e.g., Malmelin \& Villi, 2017). Follow-up research requires a broad and exploratory approach (Witschge \& Harbers, 2018) for taking into account the novel ways of working pioneered by emerging organizations.

Today, we are moving into an era of novel organizations in the news industry (Buschow \& Suhr, 2022). While these organizations are born out of changes, they are themselves social entities through which change in the field is accelerated. Our findings highlight how SMC can be seen as an organizational prototype in (science) journalism, both in terms of its contributions to the field and its ways of working. Nonetheless, the case of SMC is, in some respects, an important instance of more general transformation in the field of journalism. For example, the trend toward a shifting division of labor in journalism can be witnessed by SMC being situated in the broader context of the emergence of new organizations characterized by repackaging some activities of journalistic production (which were traditionally combined in legacy media companies) into novel organizational units.

Whether or not SMC's specific organizational design marks the rise of a new "organizational population" (Hannan \& Freeman, 1989) of actors combining field repair and field advancement under one umbrella needs to be closely monitored through follow-up research. Such a generalization is not possible from a single case study, but requires a longitudinal study of more general developments in the field.

Although SMC currently aims to improve traditional journalism rather than threaten it, follow-up research could adopt Bourdieu's (1998) field perspective in examining how SMC is seen by traditional science journalist actors, how its work impacts them, the extent to which SMC might (begin to) compete with existing players as the journalistic situation worsens (see Section 4.2.2), and how this might lead to struggles over legitimation and power (Eldridge, 2018).

Methodologically, our research was limited by the contact restrictions due to the pandemic, resulting in research that was mostly conducted online. While this can generally be considered a constraint, it also opens up new opportunities for research in digitalized working contexts which have been an exception or limited to studies specifically focusing on online work (e.g., Bunce et al., 2018). Here, we can see the need for methodological advancement.

Future research on novel media organizations should locate them in the field, vis-à-vis SMC, while looking for (practices of) field advancement to expand the concept for other cases. For such a replication in other contexts, our study provides a fruitful starting point.

\section{Acknowledgments}

The research leading to these results has received funding from the Klaus Tschira Stiftung gGmbH. We thank SMC for their willingness to participate in this research. We acknowledge the support of the German Research Foundation (DFG) and the Bauhaus-Universität Weimar within the Open Access Publishing program.

\section{Conflict of Interests}

The authors received funding from the non-profit foundation Klaus Tschira Stiftung $\mathrm{gGmbH}$, which also supports the SMC. 


\section{References}

Alexander, J. C. (2015). The crisis of journalism reconsidered: Cultural power. Fudan Journal of the Humanities and Social Sciences, 8(1), 9-31. https://doi.org/ 10.1007/s40647-014-0056-5

Bourdieu, P. (1998). Practical reason. On the theory of action. Stanford University Press.

Bowen, G. A. (2009). Document analysis as a qualitative research method. Qualitative Research Journal, 9(2), 27-40. https://doi.org/10.3316/QRJ0902027

Broer, I. (2020). Rapid reaction: Ethnographic insights into the science media center and its response to the Covid-19 outbreak. Journal of Science Communication, 19(5). https://doi.org/10.22323/2.19050208

Broer, I., \& Pröschel, L. (2021). Das Science Media Center Germany: ethnographische einblicke in die arbeitsweisen und rollen eines intermediärs zwischen wissenschaft und journalismus [The Science Media Center Germany: Ethnographic insights into the work and roles of an intermediary between science and journalism] (Working Paper No. 57). Hans-BredowInstitut. https://doi.org/10.21241/ssoar.73542

Bunce, M., Wright, K., \& Scott, M. (2018). "Our newsroom in the cloud": Slack, virtual newsrooms, and journalistic practice. New Media \& Society, 20(9), 3381-3399. https://doi.org/10.1177/14614448177 48955

Buschow, C. (2020a). Practice-driven journalism research: Impulses for a dynamic understanding of journalism in the context of its reorganization. Studies in Communication Sciences, 20(2), 227-241. https://doi.org/10.24434/j.scoms.2020.02.006

Buschow, C. (2020b). Why do digital native news media fail? An investigation of failure in the early startup phase. Media and Communication, 8(2), 51-61. https://doi.org/10.17645/mac.v8i2.2677

Buschow, C., \& Suhr, M. (2022). Change management and new organizational forms of content creation. In S. Diehl, M. Karmasin, \& I. Koinig (Eds.), Media and change management (pp. 1-17). Springer.

Caswell, D. (2019). Structured journalism and the semantic units of news. Digital Journalism, 7(8), 1134-1156. https://doi.org/10.1080/21670811.2019.1651665

Cottle, S. (2007). Ethnography and news production: New(s) developments in the field. Sociology Compass, 1(1), 1-16. https://doi.org/10.1111/j.17519020.2007.00002.x

Deuze, M., \& Witschge, T. (2020). Beyond journalism. Polity.

DiMaggio, P. J., \& Powell, W. W. (1983). The iron cage revisited: Institutional isomorphism and collective rationality in organizational fields. American Sociological Review, 48(2), 147-160. https://doi.org/ $10.2307 / 2095101$

Eisenhardt, K. M. (1989). Building theories from case study research. The Academy of Management Review, 14(4), 532-550. https://doi.org/10.2307/
258557

Eisenhardt, K. M., Graebner, M. E., \& Sonenshein, S. (2016). Grand challenges and inductive methods: Rigor without rigor mortis. Academy of Management Journal, 59(4), 1113-1123. https://doi.org/10.5465/ amj.2016.4004

Eldridge, S. A. (2018). Online journalism from the periphery: Interloper media and the journalistic field. Routledge.

Gans, H. J. (1980). Deciding what's news. Vintage Books.

Graves, L., \& Konieczna, M. (2015). Sharing the news: Journalistic collaboration as field repair. International Journal of Communication, 9(1), 1966-1984.

Hannan, M. T., \& Freeman, J. (1989). Organizational ecology. Harvard University Press.

Hermida, A., \& Young, M. L. (2019). From peripheral to integral? A digital-born journalism not for profit in a time of crises. Media and Communication, 7(4), 92-102. https://doi.org/10.17645/mac.v7i4.2269

Hettwer, H., Rödder, S., \& Zotta, F. (2012). Das britische Science Media Centre-und was wir davon lernen können [The British Science Media Centre-and what we can learn from it]. WPK Quarterly, 1(1), 16-18. https://www.wpk.org/quarterly/einzelartikel/dasbritische-science-media-centre-(smc)-und-was-wirdavon-lernen-koennen.html

Hettwer, H., Schneider, M., \& Zotta, F. (2013). Explorationsphase zur gründung eines Science Media Center (SMC) in deutschland [Exploration phase leading to the establishment of a Science Media Center (SMC) in Germany]. WPK. https://www.wpk.org/ upload/download/dokumente\%20aktuelles/ SMC_Executive\%20Summary_Abschlussbericht\% 20RBS_het_13-04-17.pdf

Holton, A. E., \& Belair-Gagnon, V. (2018). Strangers to the game? Interlopers, intralopers, and shifting news production. Media and Communication, 6(4), 70-78. https://doi.org/10.17645/mac.v6i4.1490

Jones, R., \& Jones, B. (2019). Atomising the news: The (in)flexibility of structured journalism. Digital Journalism, 7(8), 1157-1179. https://doi.org/10.1080/ 21670811.2019.1609372

Jordaan, M. (2020). An open mind, not an empty head: Towards perpetual waves of newswork ethnography. African Journalism Studies, 41(4), 51-67. https://doi. org/10.1080/23743670.2020.1785519

Konieczna, M. (2018). Journalism without profit: Making news when the market fails. Oxford University Press.

Lewis, S., \& Usher, N. (2013). Open source and journalism: Toward new frameworks for imagining news innovation. Media, Culture \& Society, 35(5), 602-619. https://doi.org/10.1177/0163443713485494

Malmelin, N., \& Villi, M. (2017). Media work in change: Understanding the role of media professionals in times of digital transformation and convergence. Sociology Compass, 11(7), Article e12494. https:// doi.org/10.1111/soc4.12494

Miles, M. B., Huberman, A. M., \& Saldaña, J. (2014). Qual- 
itative data analysis: A methods sourcebook. SAGE.

Mills, J., \& Wagemans, A. (2021). Media labs: Constructing journalism laboratories, innovating the future. How journalism is catalysing its future processes, products, and people. Convergence: The International Journal of Research into New Media Technologies. Advance Online Publication. https://doi.org/ 10.1177/1354856521994453

Nicolini, D. (2012). Practice theory, work, and organization: An introduction. Oxford University Press.

Nørskov, S. V., \& Rask, M. (2011). Observation of online communities: A discussion of online and offline observer roles in studying development, cooperation and coordination in an open source software environment. Qualitative Archives and Biographical Research Methods, 12(3). https://doi.org/10.17169/ fqs-12.3.1567

O’Donnell, P., \& Zion, L. (2019). Precarity in media work. In M. Deuze \& M. Prenger (Eds.), Making media (pp. 223-234). Amsterdam University Press.

Reese, S. D. (2020). The crisis of the institutional press. Polity.

Ridder, H. (2020). Case study research: Approaches, methods, contribution to theory ( $2 \mathrm{nd}$ ed.). Rainer Hampp.

Rödder, S. (2015). Science media centres and public policy. Science and Public Policy, 42(3), 387-400. https:// doi.org/10.1093/scipol/scu057

Rödder, S. (2020). Organisation matters: Towards an organizational sociology of science communication. Journal of Communication Management, 24(3), 169-188. https://doi.org/10.1108/JCOM-06-2019-0093
Ryfe, D. M. (2018). A practice approach to the study of news production. Journalism, 19(2), 217-233. https://doi.org/10.1177/1464884917699854

Saldaña, J. (2016). The coding manual for qualitative researchers (3rd ed.). SAGE.

Schatzki, T. R. (2005). Peripheral vision: The sites of organizations. Organization Studies, 26(3), 465-484. https://doi.org/10.1177/0170840605050876

Science Media Center Germany. (2021). Rapid reaction. https://www.sciencemediacenter.de/alle-angebote/ rapid-reaction/?tx_news_pi1\%5B\%40widget_0\%5D \%5BcurrentPage $\% 5 \mathrm{D}=2 \& \mathrm{cHash}=\mathrm{d} 07 \mathrm{ca} 51 \mathrm{cf} 4 \mathrm{~d} 3076$ c98316a12e1f5d93a

Scott, W. R. (2013). Institutions and organizations: Ideas, interests, and identities. SAGE.

Tandoc, E. C., Jr., \& Jenkins, J. (2017). The Buzzfeedication of journalism? How traditional news organizations are talking about a new entrant to the journalistic field will surprise you! Journalism, 18(4), 482-500. https://doi.org/10.1177/1464884915620269

Tuchman, G. (1973). Making news by doing work: Routinizing the unexpected. American Journal of Sociology, 79(1), 110-131.

Usher, N. (2016). Interactive journalism: Hackers, data, and code. University of Illinois Press.

Witschge, T., \& Harbers, F. (2018). Journalism as practice. In T. P. Vos (Ed.), Journalism (pp. 105-123). De Gruyter.

Yin, R. K. (2018). Case study research and applications: Design and methods (6th ed.). SAGE.

Zelizer, B. (2017). What journalism could be. Polity.

\section{About the Authors}

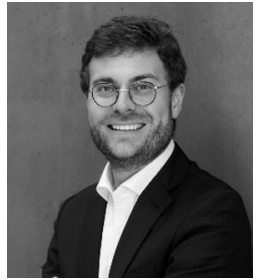

Christopher Buschow is assistant professor of organization and network media in the Media Management Department, Faculty of Media at Bauhaus-Universität Weimar, Germany. His research and teaching focus on organizing and innovating journalism, as well as on start-ups and entrepreneurship in the media industry. Buschow's work has been honored with the Lower Saxony Science Award and the German Thesis Award from the Körber Foundation.

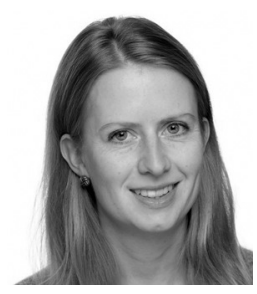

Maike Suhr is a research associate in the Department of Media Management, Faculty of Media at Bauhaus-Universität Weimar, Germany. Her current research focuses on diversity in journalism startups and novel organizational forms in journalism. Her research interests further include media and culture in the post-migrant, transnational society.

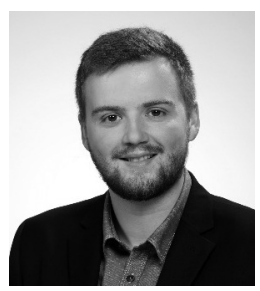

Hauke Serger studied in the Media Management program at Bauhaus-Universität Weimar, Germany, and was a student research assistant in the Department of Media Management, Faculty of Media. His current research focuses on novel organizational forms in journalism. Further research interests include digital communication and public relations in sports. 